\title{
Incidence and diversity of Neotyphodium endophytes in Bulgarian populations of Lolium perenne
}

H. HAHN ${ }^{1}$, K. ANDREEVA² and E. WILLNER ${ }^{3}$

${ }^{1}$ Martin-Luther-University Halle-Wittenberg, Institute of Agronomy and Crop Science, Ludwig-Wucherer-Str. 2, 06108 Halle, Germany

${ }^{2}$ University of Kentucky, Plant Pathology Department, 201 F Plant Science Building, 1405 Veterans Drive, Lexington, KY $40546-0312$

${ }^{3}$ Institute of Plant Genetics and Crop Plant Research (IPK), External Branch North, Inselstr. 9, 23999 Malchow/Poel, Germany heike.hahn@landw.uni-halle.de

\begin{abstract}
About 28\% of agricultural land in Bulgaria is grassland that is mainly confined to foothills, intermediate mountain areas and alpine pastures and meadows. Most permanent grassland is in a semi-natural state with limited areas of sown pasture. The larger portion of the permanent pastures is situated on infertile soils in regions of insufficient moisture. Therefore, adaptation to these conditions is a prerequisite for grass species to survive and proliferate. As endophyte infection may improve stress response of grass plants, the aim of our study was (1) to investigate the incidence of fungal endophytes in perennial ryegrass collected from such habitats, and (2) to characterise the corresponding fungal isolates.

During a collection trip to Bulgaria, 62 accessions of Lolium perenne were collected from 55 sites representing different lowland and mountain habitats. Endophytes were detected in 59 accessions by microscopic analysis of seed. Infection level varied from $>5$ to $100 \%$ with 50 out of 59 accessions showing infection levels higher than $50 \%$. Analysis of conditions at the collection sites revealed that endophyte-infected seeds were found more frequently in dry than in wet habitats, and more often at altitudes between $400-800 \mathrm{~m}$ than at other altitudes.
\end{abstract}

Isolates were obtained from surface-sterilised leaf sheath tissue placed on PDA and cultivated at $21^{\circ} \mathrm{C}$ in the dark. Characterisation of isolates was performed by the detection of the time for mycelium to emerge from leaf sheaths tissue, by morphological characteristics of the colonies and by the radial growth rate measured on PDA at $21^{\circ} \mathrm{C}$. A wide variation ranging from 5 to 27 days was found for the incubation time until mycelia emerged from plant tissue. The morphological diversity of the colonies appeared to be greater than described originally for Neotyphodium lolii. Isolates were white or tan in color, convoluted, and raised or domed in shape. Some isolates formed aerial cotton-like mycelium. Radial growth of many isolates was slow ( $<0.2 \mathrm{~mm} /$ day) but faster growing isolates were also found. Alkaloids need to be quantified for further characterisation.

The high incidence of endophytes in Lolium perenne indicates that endophyte infection may confer increased fitness to the host plant especially under unfavourable conditions such as drought. Investigations on fungal isolates are needed to provide a pool of endophyte diversity required for the development of new endophyte/grass associations for specific purposes, e.g. for the use under marginal conditions with enhanced drought tolerance or for cultivation as fodder crop with low alkaloid levels. 